\title{
Ranking Quality Management Indicators for Radio Programs
}

\author{
Chia-Kun Lee \\ I-Shou University, Kaohsiung City, Taiwan, R.O.C.
}

\begin{abstract}
Even though radio broadcasting is one of the most widespread electronic mass media, its management for survival is getting drastic. The competition among incumbent radio stations becomes challenging due to the market change and environmental evolution. Managing program quality is a critical issue to a radio station to sharpen its competitive advantages. Quality management of radio programs is intertwined with complicated factors. In order to identify the primary factors affecting radio program quality as well as explore the impact level these factors bring, this study adopts modified Delphi method and analytic hierarchy process (AHP) to explore the issues. According to the outcomes modified Delphi method, the factors were categorized into four dimensions: operation, coordination, structure, and improvement. Ten sub-dimensions were followed. Each sub-dimension includes six to nineteen indicators for measuring radio program quality. In total, 72 indicators were identified. The AHP result revealed that the most important weight was given to the operation dimension. On the contrary, the least important weight was placed on the improvement dimension. Among the sub-dimensions, the standard procedure and organizational design were rated more important than the rest. The results could provide some facts to radio managers for future management.
\end{abstract}

Keywords: quality, radio, indicators, Delphi, AHP

\section{Introduction}

As the most available and easy-access mass media, radio broadcasting serves the world with programmed information and music (Hoeg \& Lauterbach, 2004). Nowadays, the incumbent radio stations face highly competitive challenges due to technological, economic, regulatory, global and social changes (Albarran, 2013). In order to manage the traditional medium industry, mangers of radio stations pursue rational and progressive methods for survival. Instead of being overnight sensation only, developing valid plans is more reliable for good quality of radio programs (Leblebici, Salancik, Copay, \& King, 1991; Keith, 1987). Any influential factors for radio program quality should not be ignored by the managers.

The service of radio broadcasting involves numerous program providers, transmitters and receivers (Herrick, 2012). To be successful in managing good quality of radio programs, the mangers need to put innumerable factors into consideration. It is a complicated process to materialize and implement the factors. The process, from development, production, distribution to exhibition, includes many critical tasks. Assuring each task will becomes a critical issue for a radio manager (Albarran, 2013).

In the field of media management, total quality management (TQM) and system theory are the prevailing and well-applied approaches for product production and custom service. These approaches combined can develop strategies to deliver the best products and services by continuously improving every part of an

Chia-Kun Lee, Assistant Professor, Mass Communication Department, I-Shou University. 
operation (Albarran, 2013). Unlike the quality of general goods, service quality is difficult to measure in precise manufacturing specifications. It is revealed that service quality is highly dependent on the performance of practitioners, organizational resource, and interaction between administrators and employees (Herrick, 2012; Zeithaml, Berry, \& Parasuraman, 1988). In the radio industry, the quality of radio programs is associated with internal and external stakeholders. Radio managers can adopt various approaches to encourage and demand high quality in the products as well as in the process.

A radio program is involved with various factors during the production process. Each factor with its importance can differently influence a radio station due to its market, position, programming and so on. In order to help the mangers of this industry, this study aims to develop a framework to systematically integrate the factors. In addition, all the factors can be specifically illustrated for practical operation. The objectives of this study are the following:

(1) identifying the critical factors which influence radio program quality;

(2) comparing the weights of the critical factors based on practitioners' viewpoints;

(3) discussing the issues of program quality management for the radio stations.

\section{Literature Reivew}

The diverse range of management has emerged since the 1960s. The focus of management theories shifted from class and human relations schools to new approaches, such as management effectiveness, system approaches, and leadership (Albarran, 2013). Total quality management theory (TQM) was one of the most extensively implemented in the media industry for service quality control. When dealing with quality issues, system theory is inevitable because TQM is considered a system for learning new skills to benefit their service or production (Mele \& Colurcio, 2006). The systemic concept can strengthen to understand the interactive relationship between electronic media and the societal systems. Media industries do not operate independently but form part of a larger system that includes political, economic, technological, and social subsystems (Albarran, 2013; Mele, Lels, \& Polese, 2010). In this study, TQM and system theory were used to identify the critical factors which could influenced broadcast program quality and discussed the interactive relationship among these factors.

\section{Total Quality Management (TQM) Theory}

Organizations adopt quality control procedures and strategies to reverse the negative image associated with poor-quality products. In addition, TQM is used as a way to encourage and demand high quality in the products and service (Albarran, 2013). Many concepts of TQM have applied in electronic media, from actual production of media content and advertising to the use of mission statements and public relations activities.

Defining quality is difficulty due to its multiple dimensions. In addition, quality cannot only refer to objects and goods, but also to tangible/intangible performance and service. According to International Standard Organization, quality is considered to be the competence which satisfies specific needs by its features or characteristics from goods or service. The definition of quality can be identified by five approaches (Garvin, 1984):

(1) The transcendent approach of philosophy;

(2) The product-based approach of economics;

(3) The user-based approach of economics, marketing and operations management; 
(4) The manufacturing-based approach;

(5) The value-based approaches of operations management.

These approaches reveal four major coverages of quality issues. Philosophy focuses on its definitional issues, while economics pursues profit maximization and market dynamics. Marketing emphasizes the determinants of purchase behavior and customer satisfaction, but operations management focuses on practical operation and manufacturing control. It results in various perspectives of quality management based on the terminology.

Total quality management is a prevailing management approach in many fields, including business, engineering, health care, education and administration (Dean \& Bowen, 1994). The meanings of total quality management have been discussed by various scholars. Crosby (1979) focused on controlling cost through quality improvement and stressed that both high- and low-end products can have high quality. Deming's (1986) emphasizes the systemic nature of organizations, the importance of leadership and the need to reduce variation in organizational processes. Juran's (1989) framework indicates three sets of activities-quality: planning, control, and improvement, which also emphasizes the use of statistical tools to eliminate defects. Sallis (1993) considered it a kind of philosophy which focuses on continuous improvement. It is also a series of practical tools to satisfy and surpass needs and expectation from current and future customers.

According to the definitions or explanation above, total quality management is involved with all stakeholders. Everyone is responsible for quality. From inputting to outcomes, it takes appropriate strategy and methods to meet specific standards or customers' needs. In a word, the concept of total quality management is associated with practitioners, process and product. In the media industry, these three aspects also work for product quality. In a radio station, the control process of program production has to be established and developed. Radio practitioners are supposed to be well trained in techniques of program production as well as appropriate mindsets for excellence. Programs are the products of a radio station, which have to meet audience's needs or interests.

\section{System Theory}

System theory is an interdisciplinary theory which emphasized every system in nature, in society or in many fields. It argues that a phenomenon cannot simply be understood by breaking it into elementary parts and then reforming it. It encourages taking a holistic approach to comprehend phenomena (Jachson, 2003). Systems theory was proposed in the 1940's. Ludwig von Bertalanffy is considered as the founder of general system theory. He defined a system as a complex of interacting elements and fostered system thinking in all disciplines to pursue general principles. This theory introduced system as a new paradigm to contrast to classical science which characterized analytical and mechanical paradigm (Ryszard, 2014; Jackson, 2003; Kast \& Rosenzweig, 1995).

According to the system approach, a system is defined as an entity with interdependent parts as a coherent whole for specific purposes. A real system is open to, and interacts with its environment, which a boundary is perceived to distinguish internal and external elements and to identify its operation of the entity (Daryani, Ali, \& Asli-zadeh, 2012; Mele, Lels, \& Polese, 2010). The basic functions of a system included (Ryszard, 2014; Potocki \& Brocato, 1995): (1) input: comes from sensing the environment; (2) process: is the process that people using technology and methods to do analysis and make decisions; (3) output: refers to the response of the system to the input; (4) feedback: collects the response from the environment for revision or improvement. The infrastructure illustrates how a system working with subsystems to complete the goal, including planning, information, communication, technology, and process control. 
The system approach to management just provides a macro perspective to explore the development of an organization with the internal and external factors. An organization is not an isolated entity, which has to interact with other objects and organization in the environment. An organization interacts with the environment to complete the input-process-output-feedback operations, and then strives for optimization (Albarran, 2013; Potocki \& Brocato, 1995). In an organizational context, a system represents a number of people, processes, technologies, and materials that collaborate and coordinate accordingly to achieve a significant function and contribute to a specific service or product development. In general system theory can help media managers understanding the interactive relationship between media and the society, in which media industries strive for a state of balance with political, economic, technological and social conditions and optimize their service products.

\section{Methods and Procedures}

In order to collect data to complete the research objectives, two methods were adopted: modified Delphi method and analytic hierarchy process (AHP). The former method aimed to identify the critical factors of radio program quality management as indicators, while the latter was used to evaluate the relative weights among the indicators. Combing these two methods could determine the importance level of the indicators, which could lead to understand how radio stations deal with program quality management.

Modified Delphi method is a group decision-making technique, which was initially developed by Rand Company, USA, in 1950. By structurally communicating in an expert group, the specialists involved canparticipate and express their voices, and finally reach final agreements without face-to-face interaction (Wang, Gao, \& Guo, 2012). In 1995, Murry and Hommons developed modified Delphi method to fix the shortcomings of the original one: time consuming, control difficulty and contradictions over time. Unlike the old method using open-structure questionnaires to create conversations among experts, the new approach develops its questionnaire by organizing relevant literature in the very beginning. This difference can not only save time, but also help experts focusing on the issues (Scarcella, Stewart, \& Custer, 1999; Delbecq, Van de Ven, \& Gustafson, 1975).

Another method used in this study was analytic hierarchy process, which was developed by Thomas Satty in 1971. It is a technique to help mangers to optimize decision making when facing with a mix of qualitative, quantitative, and sometimes conflicting factors for consideration. AHP has been very effective because it just simplified and categorized factors into a hierarchical system and derives ratio scales from paired comparisons of factors and choice options (Satty, 2008). In practical reality, decision making involves many criteria and sub-criteria with mutual influence on each other. No matter being tangible or intangible, the complicated relationship among the criteria challenges managers' expertise. When making decisions, not only managers should set up priorities for the alternatives, but also identify the best choice (Bhushan \& Ria, 2004). Nowadays, it is applied to many fields and organizations. Typically, this method is usually used to prioritizing factors and requirements, or choose among strategies, or estimating cost and scheduling options, selecting component vendors, or evaluating quality of proposals or plans (Teknomo, 2006). This technique can reduce the risk of making wrong decisions, and provide full comparison among multiple factors for selecting best choice.

This study aimed to explore the factor influencing radio program quality at first. There were various factors involved in the production process of radio programs. The stakeholders, such as radio administrators, program specialists, audiences and the other participants, could make difference for radio products. In order to 
identify these valid factors, this study recruited 7 experts and scholars to analyze and convert the internal and external environments of a radio station into the indicators. It took three runs of group discussion to reach the consensus. Afterwards, the AHP method was used to determine the relative weights of the indicators. 24 radio practitioners were recruited to measure these indicators based on their experiences and insights. After calculating the returned questionnaires, the final outcome revealed the weights given by the practitioners to the indicators.

\section{Findings and Discussion}

\section{Identifying the Indicators of Radio Program Quality Management}

According to literature, there were many primary concepts mentioned related to radio program quality management. In terms of TQM theory, radio program quality management comprised three aspects: (1) It is a process of continuous improvement in all aspects; (2) All the units or employees involved in the process take responsibility; (3) Its final goal is not only for quality maintenance and management, but also enhancing service to meet customers' needs. In a word, the term "total" refers all units or employees involved should be responsible. The term "quality" relates to the process and production that have to meet the expected standards and customers' needs. The term "management" represents the effective methods and means to achieve the goals. According to the system theory, the process of radio program production was examined. Broadcasting programs have to adapt to environmental change to meet customers' needs. Therefore, the radio practitioners can enhance their service by the feedback from audience. Evaluation plays a critical role not only for the final programs, but also the process. When the evaluation-improvement process turns into a positive cycle, the programs can be more appealing. The quality management mechanism embedded in a radio station comprised two aspects: content and structure. The content aspect is associated with internal standards of product quality as well as the production process, while the structure aspect explores the specific workforce and regulation for quality maintenance and management. In order to integrate these two aspects into practice, many tasks, such as experts for quality check, communication among practitioners, and standards for quality check, are involved,

This study integrated two theories above to conduct the questionnaire of modified Delphi method. According to the findings, the potential factors which could influence radio program quality were categorized into four dimensions: operation, coordination, structure, and improvement.

(1) The operation dimension refers to formal procedures and documents of quality control in a radio station.

(2) The coordination dimension defines believes of program quality plus communication among radio practitioners.

(3) The structure dimension is relevant to internal and external factors which are put into consideration for managing radio program quality.

(4) The improvementdimension focuses on evaluation mechanisms and progress strategies for quality control.

The coordination dimension comprises four sub-dimensions while the rest respectively comprise two sub-dimensions. In the operation dimension, the two sub-dimensions are standard procedures and organizational design. The coordination dimension includes administrative promises, practitioner attitudes, professional training and communication mechanisms. The structure dimension is dealing with external and internal factors. Two sub-dimensions in the improvement dimension are performance evaluation and 
continuous reform. Table 1 showed the statistics of each dimension and sub-dimension. Each sub-dimension includes six to nineteen indicators for measuring radio program quality. In total, there are 72 indicators within this framework.

Table 1

Modified Delphi Method Results

\begin{tabular}{|c|c|c|c|c|c|}
\hline Dimension & Sub-dimension & Mean & Mode & S.D. & Q.D. \\
\hline \multirow[t]{2}{*}{ Operation } & Standard Procedure & 4.57 & 5 & 0.54 & 0.5 \\
\hline & Organizational Design & 4.86 & 5 & 0.38 & 0 \\
\hline \multirow[t]{4}{*}{ Coordination } & Administrative Promises & 4.43 & 4 & 0.54 & 0.5 \\
\hline & Practitioner Attitudes & 4.86 & 5 & 0.38 & 0 \\
\hline & Professional Training & 4.86 & 5 & 0.38 & 0 \\
\hline & Communication Mechanisms & 4.71 & 5 & 0.49 & 0.5 \\
\hline \multirow[t]{2}{*}{ Structure } & Internal Factors & 4.43 & 5 & 0.79 & 0.5 \\
\hline & External Factors & 4.71 & 5 & 0.49 & 0.5 \\
\hline \multirow[t]{2}{*}{ Improvement } & Performance Evaluation & 4.71 & 5 & 0.49 & 0.5 \\
\hline & Continuous Reform & 4.71 & 5 & 0.49 & 0.5 \\
\hline
\end{tabular}

Seven experts were recruited to join the group discussion. They went through the questionnaire for phraseological revision. Meanwhile, they also checked the importance for each indicator. After 3 runs of group discussion, the quantitative data of the method indicated that most of the factors from the questionnaire just worked feasibly for this study. Only slight phraseological modification were applied to some indicators.

\section{Ranking the Indicators of Radio Program Quality Management}

Even though each indicator identified by modified Delphi method could have its impact on radio program quality, it is hard to distinguish to measure the importance level among them. The study then adopted analytic hierarchy process to measure the weight for each indicator based on 24 radio practitioners' evaluation. Table 2 showed the result of this method. The result revealed that the operation dimension is the most important over the other three. The radio practitioners believed that radio stations should build quality control unit with the experts to maintain the program quality. Also, the procedure and documents should be available for quality management. The coordination and structure dimensions were second to the operation dimension. The practitioners considered that the improvement dimension was the least important.

Table 2

AHP Results

\begin{tabular}{|c|c|c|c|c|c|}
\hline Dimension & Weight & Sub-dimension & $\begin{array}{l}\text { Weight in } \\
\text { sub-dimension }\end{array}$ & $\begin{array}{l}\text { Weight in the } \\
\text { system }\end{array}$ & Ranking \\
\hline \multirow[t]{2}{*}{ Operation } & 0.295 & Standard Procedure & 0.528 & 0.143 & 1 \\
\hline & & Organizational Design & 0.472 & 0.128 & 2 \\
\hline \multirow[t]{4}{*}{ Coordination } & 0.262 & Administrative Promises & 0.237 & 0.091 & 5 \\
\hline & & Practitioner Attitudes & 0.326 & 0.126 & 4 \\
\hline & & Professional Training & 0.218 & 0.084 & 7 \\
\hline & & Communication Mechanisms & 0.219 & 0.084 & 7 \\
\hline \multirow[t]{2}{*}{ Structure } & 0.259 & Internal Factors & 0.326 & 0.061 & 10 \\
\hline & & External Factors & 0.674 & 0.127 & 3 \\
\hline \multirow[t]{2}{*}{ Improvement } & 0.184 & Performance Evaluation & 0.574 & 0.089 & 6 \\
\hline & & Continuous Reform & 0.426 & 0.066 & 9 \\
\hline
\end{tabular}


Among the sub-dimensions, the standard procedure and organizational design were rated more important than the others. This was in line with the ranking of the dimensions. The participators also indicated that external factors were the third important, which implied the practitioners' concerns to the environmental change. Practitioner attitudes and administrative promises, which belong to the coordination dimension, were next to external factors. It indicated that the radio practitioners agreed radio administrators and program practitioners are critical to radio program quality. The least important sub-dimension included internal factors and continuous reform. These results provided interesting facts for radio managers to ponder how to improve the internal conditions and continue improvement for better program quality.

\section{Discussing the Issues of Radio Program Quality Management}

The study investigated the indicators of radio program quality management and measured the weight for each indicator. The results revealed some management issues of radio program control. The first fact was the operation dimension was the most expected, which indicated radio stations should develop the quality management system. In order to provide quality service to audience, radio managers should assure whether the quality management system is operational.

Even though evaluation can provide feedback for quality management, the results indicated that the improvement dimension was the least important. Also, the continuous reform was the least important sub-dimension. This fact uncovered that radio practitioners do not pay attention to continuous progress. However, the market competition is getting drastic. Radio practitioners should find the ways to respond to the environmental change rather than follow the routines.

In terms of the coordination dimension, radio practitioners indicated that all radio members should be involved in program quality management. That just echo to the TQC theory: all members are responsible to product quality. Radio practitioners expect that no matter being administrators or radio practitioners, all should take part in radio quality management. However, radio practitioners considered communication mechanism for quality management is relative less important. That was another fact that radio managers should be aware.

Speaking of the structure dimension, radio practitioners focus more on external factors than internal factors. It seems that environmental change really brings challenges to them. Technology, globalization, social and economic change and so on change the way of program production, which radio practitioners need to keep up. On the contrary, internal factors do not cause as much attention as expected. How do radio practitioners look at radio broadcasting? That becomes an interesting issue that radio managers can explore in the future.

\section{References}

Albarran, A. (2013). Management of electronic media. Wadsworth.

Bhushan, N., \& Ria, K. (2004). Strategic decision making: Applying the analytic hierarchy process. London: Springer-Verlag London Limited.

Crosby, P. B. (1979). Quality is free: The art of making quality certain. New York: New Amer-ican Library.

Daryani, S. M., Ali, S., \& Asli-zadeh, A. (2012). Organizational theory, systemic thinking and system management. International Journal of Organizational Leadership, 1(2), 71-79.

Dean, J. W., \& Bowen, D. E. (1994). Management theory and total quality: Improving research and practice through theory development. Academy of Management Review, 19(3), 392-418.

Delbecq, A. L., Van de Ven, A. H., \& Gustafson, D. H. (1975). Group techniques for program planning: A guide to nominal group and Delphi processes. Chicago: Scott, Foresman and Company.

Deming, W. E. (1986). Out of the crisis. Cambridge: Massachusetts Institute of Technology Press.

Garvin, D. A. (1984). What does product quality really mean? Sloan Management Review, 26(1), 25-43. 
Herrick, D. F. (2012). Media management in the age of giants: Business dynamics of journalism (2nd ed.). Iowa: University of New Mexico Press.

Hoeg, W., \& Lauterbach, T. (2004). Digital audio broadcasting: Principles and applications of digital radio. John Wiley \& Sons. Jackson, M. (2003). Systems thinking: Creative holism for managers. Chichester: John Wiley \& Sons, Ltd.

Juran, J. A. M. (1989). Juran on leadership for quality. New York: Free Press.

Kast, F. E., \& Rosenzweig, J. E. (1995). General systems theory: Applications for organization and management. Academy of Management Journal, December, 447-465.

Keith, M. C. (1987). Radio programming: Consultancy and formatics. Boston: Focal Press.

Leblebici, H., Salancik, G. R., Copay, A., \& King, T. (1991). Institutional change and the transformation of interorganizational fields: An organizational history of the US radio broadcasting industry. Administrative Science Quarterly, 36, 333-363.

Mele, C., \& Colurcio, M. (2006). The evolving path of TQM: Towards business excellence and stakeholder value. International Journal of Quality and Reliability Management, 23(5), 464-489.

Mele, C., Pels, J., \& Polese, F. (2010). A brief review of systems theories and their managerial applications. Service Science, 2(1/2), 126-135.

Potocki, K. A., \& Brocato, R. C. (1995). A system of management for organizational improvement. Johns Hopkins Apl Technical Digest, 16(4), 402-412.

Ryszard, B. (2014). Strategic management: Formulation and implementation. Retrieved from http://www.introduction-to-management.24xls.com/en132

Saaty, T. L. (2008). Decision making with the analytic hierarchy process. International Journal of Services Sciences, 1(1), 83-98.

Sallis, E. (1993). Total quality management in education. London: Kogan Page.

Scarcella, J. A., Stewart, B. R., \& Custer, R. L. (1999). The modified Delphi technique-A rotational modification. Retrieved from http://scholar.lib.vt.edu/ejournals/JVTE/v15n2/custer

Teknomo, K. (2006). Analytic Hierarchy Process (AHP) Tutorial. Retrieved from http://people.revoledu.com/kardi/tutorial/AHP/

Wang, X., Gao, Z., \& Guo, H. (2012). Delphi method for estimating uncertainty distributions. Information: An International Interdisciplinary Journal, 15(2), 449-460.

Zeithaml, V. A., Berry, L. L., \& Parasuraman, A. (1988). Communication and control processes in the delivery of service quality. The Journal of Marketing, 52(2), 35-48. 